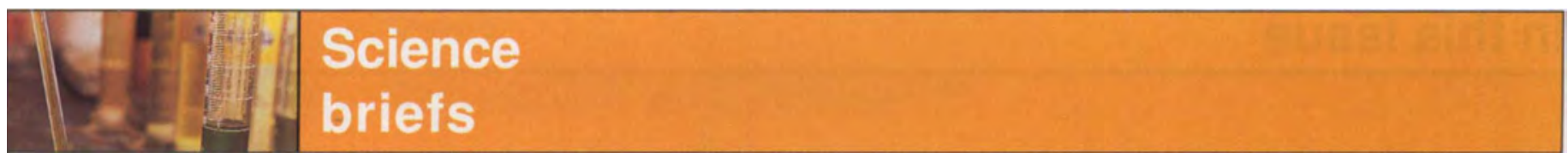

\title{
Fatal injuries to children on farms
}

Farm children between the ages of 10 and 15 have the highest rate of fatal farm injuries in California, according to a study by Dr. Marc Schenker, Professor of Medicine at UC Davis and Director of the UC Agricultural Health and Safety Center at Davis.

Injuries involving machinery are the leading cause of farm fatalities among children in California, and are 100 times more likely to be the cause of a fatal farm injury than a non-farm death. While the rate of fatal injuries to children in California agriculture was lower than for midwestern states where it has been studied, the toll is still disturbing because the deaths are preventable. Many of the machinery-related injuries are the result of children operat-

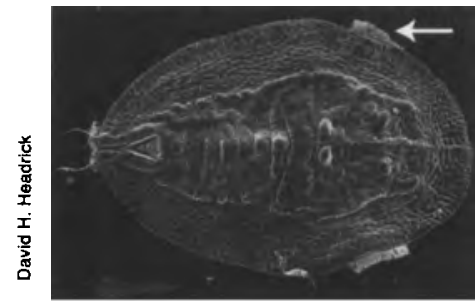
ing equipment that is not designed for them, or that lacks proper safeguards.

"Our findings suggest two immediate priorities," Schenker said. "Further study is needed to determine what causes these accidents and how to prevent them. They may involve human behaviors, engineering designs and environmental factors. In addition, the data should be used in an outreach effort to inform farm and farmworker families of hazards to children."

\section{New whitefly named as species}

The whitefly that has caused more than $\$ 1$ billion in crop damage nation-

Arrows denote wax at the marginal opening of tracheal folds of late nymphal stages of Bemisia argentifolii (top) and Bemisia tabaci (bottom) shown in this scanning electron micrograph. The size of these wax extrusions provide a simple way to tentatively identify the two species. \section{wide now has a Latin scientific name, officially} designating it as a distinct species. UC Riverside scientists who describe the species in the March 1994 issue of the Annals of the Entomological Society of America have named the silverleaf whitefly Bemisia argentifolii Bellows \& Perring. Co-authors of the article are UCR entomologists Tom S. Bellows and Thomas M. Perring; Ray Gill, California Department of Food and Agriculture entomologist and taxonomist; and David Headrick, UCR postdoctoral entomologist.

Other entomologists have considered the silverleaf whitefly to be a strain of the sweetpotato whitefly, Bemisia tabaci (rather than a different species). However, in 1993, Perring's lab in collaboration with other UCR scientists identified the new whitefly as genetically distinct from the sweetpotato whitefly and found that the two whiteflies could not mate with each other. The research was published in the journal Science. Other scientists are conducting further research that may confirm or refute its designation as a species.

Identification of the silverleaf whitefly as a distinct species may lead researchers to its origin and natural enemies. Scientists are seeking environmentally and economically sound management strategies to control the prolific insect, which feeds on numerous crops. These include biological control, cultural practices, and efficient use of selective insecticides.

In California alone, the silverleaf whitefly has caused an estimated $\$ 350$ million in crop damage since 1990 and has largely supplanted the sweetpotato whitefly.

\section{Researchers to investigate spider eating habits}

Anecdotal evidence from growers that spiders suppress vineyard pests is being put to the test by Kearney Agricultural Center scientists Kent Daane and Michael Costello, who are looking for direct proof from the spiders' stomachs.

"We don't know all the types of prey spiders feed on in the field," said Costello, a UC postdoctoral researcher. "And for this reason we don't know what role they play in biological control of insect pests."

To discern which spiders eat leafhoppers, Costello and Daane, a UC Berkeley biological control specialist, are trying serological gut analysis. But first they must isolate an antibody that can be used to detect the presence of leafhoppers in spider stomachs.

"Through this method, we have the potential to quickly screen dozens of predators, not just spiders, to help determine which is best for control of leafhoppers," Daane said.

Variegated leafhopper is a common vineyard pest which damages grape leaves and flies into pickers' eyes, noses and ears. Most growers spray insecticides to control leafhoppers, but by identifying spiders that prey on them, Costello 
and Daane may be able to suggest other ways to keep the pest in check.

\section{Farm advisor unravels oak mystery}

Blue oaks on Kern County's foothill rangeland seemed to be vanishing, but livestock farm advisor Ralph Phillips suspects they were simply overlooked in a misunderstanding of oak tree biology.

A 1987 study revealed that, on average, an acre of Kern County rangeland had about 80 seedlings (less than 1 foot tall), 75 saplings ( 1 to 5 feet tall), but only 15 trees in the 5 - to 10 -foottall range. However, there were 85 trees per acre taller than 10 feet.

Perplexed by the small number of oaks 5 to 10 feet tall, Phillips undertook a study. In 1989, he marked 605 oak seedlings at three sites in Kern County to trace their survival, then recorded the exact height of each seedling (all under 1 foot tall). Phillips' study coincided with the 19861992 drought.
During the first 4 years, rodents killed $3 \%$ of the trees. The average height of the remaining seedlings actually fell three-quarters of an inch. The a pex bud was present on virtually every seedling, indicating that grazing was not a factor.

"The oak is a unique tree," Phillips said. "The seedlings would send up a green shoot in the spring. By the end of summer, the shoots dried up and the leaves fell off. The next spring a new green shoot appeared. Moisture needed for growth was limited, so each new shoot was smaller than the previous year's shoot."

In 1990, Phillips began to research the age of his 605 trees. "We were very surprised to find that close to $20 \%$ of the seedlings (all under 1 foot tall) were over 10 years old," he said. "One tree less than 6 inches tall was over 25 years old."

Phillips thinks the small trees form a reservoir of oaks that grow tall only when conditions allow, such as when more water is available or a nearby mature oak dies.

$$
\text { - Editor }
$$

\section{Research update}

\section{Economists calculate research payoff, effect of cuts}

A gricultural research and development is the chief reason California farm output increased nearly 3-fold from 1949 to 1985, while inputs rose only 1.6-fold, says a new report from UC's Agricultural Issues Center.

Valuing UC Agricultural Research and Extension documents the role of research in California's economic growth, but cautions that the decline in public funds for research since 1991 may put the state's vibrant agricultural economy at risk.

The authors estimate that the average annual return on publicly funded agricultural research is about $20 \%$, which compares favorably to the rates at which government could invest.

"On that basis, this has been a good investment for society," said Julian Alston, one of the study's authors. "However, this estimate is conservative compared with many studies indicating returns of 30 to $70 \%$ annually."
To compute the rate of return, the economists first compared the stream of yearly research benefits from 1949 through 1985 with the stream of research expenditures from 1914 to 1985 . Because the study did not account for research benefits before 1949 and after 1985, the result a $21.4 \%$ average annual return - was conservatively low.

"However, previous estimates may have understated costs by not allowing for the full cost to society of using tax revenues, and by excluding some associated overhead costs such as basic research," Alston said. "Also, benefits may have been overstated by disregarding effects of private research and government commodity programs."

Because not all productivity growth can be attributed to public sector research, the authors then supposed that half of the measured benefit 